\title{
Teaching Reform of Computer Composition and Structure based on IEET Engineering Certification Environment
}

\author{
Jubao Qu ${ }^{\mathrm{a},}$, , Hongtao Liang ${ }^{\mathrm{b}}$, and Xiaofei $\mathrm{Li}^{\mathrm{c}}$ \\ School of Mathematics and Computer, Wuyi University, Wuyishan, Fujian 354300, China \\ adojbok@qq.com, ${ }^{b}$ wyxyqjb@163.com,wyxyjsj@qq.com
}

Keywords: IEET, engineering certification, computer composition and structure, teaching reform.

Abstract: According to the IEET certification standard and the current teaching situation of Computer Composition and Structure, a series of measures are put forward, such as changing teachers' teaching ideas, reorienting curriculum functions, reforming teaching methods and content system, and strengthening engineering practice training. Practice has proved that the reform effect is good.

\section{Introduction}

A The Washington Agreement was initiated and signed in 1989 by non-governmental engineering professional groups from the United States, Britain, Canada and other six countries. It specifies the competencies and knowledge standards required to meet the standards of engineers at all levels. It aims to bridge the differences in engineering education processes in different countries with scientific standards, but in terms of training results. The unified index reached. Document [1] points out that the person who has obtained the certification of the project will be recognized as a qualified professional education by the registered engineer institutions of other Member States, and can apply to become a registered engineer in that country, thus realizing the international mutual recognition of engineer qualifications. Document [2] points out that IEET (Institute of Engineering Education Taiwan) project certification is a Taiwan professional appraisal institution with international certification qualification of Washington Agreement approved by the Ministry of Education of China. According to the arrangement of Fujian Education Department, computer science and technology major of Wuyi College began to accept IEET professional certification in 2016. Document [3] points out that compared with IEET professional certification evaluation index system, there are great differences between IEET professional certification evaluation index system and traditional education in terms of training objectives, graduation requirements, curriculum system and teaching evaluation methods. It is necessary to make corresponding adjustments to existing professional training programs, curriculum teaching and other aspects, and to establish a good teaching evaluation. China's engineering education will be recognized by other member states in order to lay the foundation for ensuring that the quality of computer professional training meets the international requirements. 


\section{Teaching situation and existing problems}

According to the requirements of IEET engineering certification standard, computer majors must have the ability of hardware system and application development, system integration and application. Computer Composition and Structure, as one of the core courses of computer specialty, focuses on training students'hardware ability and system integration ability. Document [4] points out: however, the course is generally acknowledged to be hard to learn and boring. The main manifestations are as follows: (1) The theoretical content is relatively abstract, and the relevant knowledge points involved in the course are more, involving not only hardware knowledge such as electronic technology, but also software knowledge such as programming, which is really difficult for students who are not well-grounded and forget while learning; (2) the latest development of the textbook relative to the subject. The state lags behind, and it can't show the characteristics of high-speed development of computer very well. Many new knowledge and technology can't be reflected in the current textbooks; (3) experiment design and update are not timely, many students just meet the steps of the experiment guide to complete the experiment process, and they don't really understand the purpose and intention of the experiment. The aging of testing equipment and technology can not reflect the latest design and manufacturing technology, which makes students useless; (4) Over-reliance on Multimedia Courseware in classroom teaching leads to simplification of logic deduction and dynamic analysis process, which hinders the cultivation of students'continuous thinking ability; (5) Students' knowledge and ability need to be improved. Step by step. Teachers and students themselves do not understand the training of students' abilities.

\section{Reform of teachers' teaching ideas}

According to the requirements of IEET Engineering Certification Standard, computer science and technology students should have eight core competencies after graduation: (1) the ability to use mathematical, scientific and engineering knowledge; (2) the ability to design and execute experiments, as well as to analyze and interpret data; (3) the ability to execute computer software design, application development, system integration and maintenance. Management, training, teaching and other computer engineering practices required technology, skills and the ability to use modern tools; (4) Hardware systems, application development, system integration applications, analysis and design capabilities; (5) Computer system project management (including funding planning and cost budget), effective communication, domain integration and team work capabilities Strength; (6) Explore, analyze and apply the research results of computer science and technology related fields and the ability to deal with complex and comprehensive engineering problems; (7) Understand the situation at home and abroad and the cutting-edge information of the development of computer science and technology disciplines, be familiar with the impact of computer science and technology on the environment, society and the world, and cultivate sustainability. Habits and abilities of learning; (8) Humanities and Social Sciences literacy and social responsibility, understanding and application of professional ethics and respect for multiple perspectives.

\section{Reorientation of curriculum functions}

Computer Composition and Structure is one of the core courses of computer science and technology specialty, and it is an effective educational link to train computer system analysis and system design. This course analyses the basic composition and working principle of electronic and digital computer from the bottom, which can help students break the mystery of computer, master the basic design technology of computer system, and cultivate students'ability to analyze and solve 
practical problems of digital system. Starting from the Von Neumann model, the course systematically teaches computer internal structure, functional components, functional features, working principles, interactive methods and basic design methods. The curriculum has both the computer theory knowledge of abstract concept and difficult understanding, and the characteristics of practicality. Therefore, in the course of teaching this course, it is necessary to make students understand the organization structure and working principle of computer hardware system systematically, master the basic analysis and design methods of computer hardware system, in order to cultivate the recognition of computer hardware system, through the combination of course teaching, course experiment and course design. The design and innovation ability lays a good foundation. There are many teaching contents and learning difficulties in the course. It is necessary to grasp the overall structure and working principle of computer hardware system from a global or macro perspective, and to understand the working process and interaction mode of computer components from a local or micro perspective.

\section{Reform of teaching methods}

Traditional teaching methods can not directly and vividly describe the process and principle of computer internal composition, and the teaching content is difficult to be fully understood and mastered by students through classroom teaching. Therefore, making and designing corresponding electronic teaching plans and developing multimedia courseware can increase the amount of information in classroom teaching. The animation form of multimedia courseware can directly and vividly express the abstract working principle and working process inside the computer, and intuitively display the information flow in each step of each component. The dynamic process is displayed in front of the students in a vivid way. For example, when teaching the execution process of instruction flow in CPU, the above-mentioned assistant teaching methods can make students see more clearly the dynamic execution process of each instruction under the command of the controller, enrich students'imagination, enhance students' interest in learning, and make the dull teaching process lively and abstract. The difficult concepts become intuitive and clear. Therefore, organizing teaching contents, researching teaching methods and designing practical experimental teaching contents are helpful for students to master the knowledge unit of the course from the micro level, to establish the knowledge system of the course from the macro level, and to cultivate students'cognitive ability, design ability and innovation ability about computer hardware system. Important role.

\section{Teaching content reform}

This course is usually composed of two courses: Principles of Computer Composition and Computer Architecture. Although there is little difference in teaching content between domestic and foreign universities, according to their own characteristics and professional orientation, there are still some deficiencies in the organization of course content, the focus of knowledge and the promotion of hierarchy. Other. With the rapid development of computer technology, the cycle of new technology and new theory from being put forward to practical application is very short. It is necessary to introduce new knowledge and new technology in limited teaching time, increase students'interest in learning and solve practical problems. Therefore, the choice of content includes two aspects: first, in the course of classroom teaching, we should teach the composing principle and internal working mechanism of computer components and systems, introduce the latest research results and technical applications of each component in time, such as introducing the concept of multi-level Cache in time when teaching the Cache part; and second, we should introduce the concept of multi-level Cache in time when teaching the Cache part. In the same processor, multi-core technology is introduced; in the 
teaching of pipelining technology, superscalar pipelining and disorderly execution are introduced. The second is to introduce the latest design and implementation methods and technologies in practice, such as EDA technology, virtual reality technology, etc. to complete the design of functional components, as well as the design and debugging of the whole model.

\section{Reform of practice link}

IEET certification attaches great importance to practical teaching, which can be better reflected in the course of Computer Composition and Structure. Through practical teaching, students can penetrate into the interior of the computer, check and test the working status of the main signals and components, modify the realized design, add their own new design, combine theoretical knowledge with practice, and deepen the understanding and mastery of theoretical knowledge. Through practical teaching, we can cultivate students'practical ability, improve their interest in learning and enhance their innovative consciousness. In order to achieve these goals, we have carried out three reforms in practical teaching, namely, the reform of traditional experimental box teaching mode, the reform of project-based experimental teaching mode and the reform of hierarchical experimental teaching. Leather has gained satisfactory results in teaching practice in recent years.

\section{Reform effect analysis}

Last year our Wuyi college computer science and technology professional participated in IEET certification. All teachers and students of this profession have passed the IEET project certification with very satisfactory results. One of the core certification courses is Capstone, which considers the students'comprehensive abilities best. Table 1 shows the students' comprehensive scores in this course. The results of Capstone course are composed of three parts: the evaluation results of the instructor, the evaluation results of the two teachers on the project report and the results of the project reply. As can be seen from table 1, the results are mainly distributed in good times.

Table 12017 summary of Capstone student achievement

\begin{tabular}{cccccc}
\hline Equal grades & $\begin{array}{c}\text { excellen } \\
\mathrm{t}\end{array}$ & good & $\begin{array}{c}\text { secondar } \\
\mathrm{y}\end{array}$ & pass & Fail \\
\hline $\begin{array}{c}\text { Student number } \\
\text { Proportion }\end{array}$ & $9.62 \%$ & 50 & 44 & 0 & 0 \\
\hline
\end{tabular}

\section{Conclusion}

Engineering education certification is an inevitable trend for engineering majors to promote professional development, improve the quality of personnel training, enhance the adaptability of the talent industry, and enter the international talent market. IEET certification pays great attention to the cultivation of students'teamwork ability, practical ability and innovative ability. Therefore, according to the IEET certification standard and the current teaching situation of the core course Computer Composition and Structure, this paper puts forward a series of teaching reforms, such as changing the teaching methods of teachers'education, rethinking the functions of the courses, and carrying out a series of teaching reforms on the teaching methods, contents and practical links of the courses. The certificate and high pass rate indicate that the teaching reform of the course is successful.

\section{Acknowledgments}

This research was financially supported by The Key Laboratory of Cognitive computing and 
intelligent information processing of Fujian Education Innovation, Fujian Provincial Higher Education Innovation and Entrepreneurship Education Reform Project (sjzy2017002), Fujian Provincial University "Curriculum Thought" Education and Teaching Reform Project (KC18087), Fujian Provincial Natural Science Foundation Project (2017J01406).

\section{References}

[1] YanBo Wu. 2017. Discussion on the teaching of computer organization principles. Fujian computer. Vol. 9 (64-65). [2] Shi Zhenghao, Zhao Minghua, Li Peng and Wang Yinghui. 2013. Exploration and Practice of Teaching Reform of Computer Composition and Architecture. Teaching Research. Vol.2 (64-67).

[3] Chen Guotie, Wang Jian. 2014. The status quo and Enlightenment of IEET engineering education professional certification in Taiwan. China Construction Education. Vol. 1(50-54).

[4] Huang Lida. 2016. Exploration and practice in the teaching of computer composition and structure. Computer Education Vol. 10 (141-144). 